\title{
Espectro y verdad en Labio de liebre (venganza o perdón) de Fabio Rubiano o del teatro subversivo en tiempos inextricables
}

\author{
Juliana Espinal/ University of California, Los Angeles
}

Labio de liebre (venganza o perdón) es una obra de teatro escrita, dirigida y protagonizada por Fabio Rubiano y su grupo Teatro Petra. Este artículo se basa en la grabación que el propio grupo hace de la puesta en escena la noche de su estreno el 5 de marzo del $2015 .{ }^{1}$ La trama de la pieza gira en torno a Salvo Castelo, un paramilitar (aunque esto no se menciona explícitamente) que, en el marco de un proceso de justicia transicional, paga en tierras extranjeras una condena de tres años por los crímenes que cometió. Una noche, Salvo recibe una visita del pasado. Se trata de una familia de fantasmas, los Sosa, que viene para confrontarlo. Ellos buscan la justicia y la verdad que la ley no les ha garantizado: quieren que su victimario los reconozca, acepte lo que les hizo, confiese dónde ha dejado sus cuerpos y les devuelva los objetos materiales que les fueron arrebatados en el momento del asesinato: un reloj, una gallina, un perro y sus instrumentos musicales (Rubiano 2015a, 49).

Salvo niega conocerlos, haberlos visto antes o saber dónde están las cosas que reclaman. En última instancia, niega haber cometido un crimen. La obra se construye, de esta forma, en lo que en términos de Elizabeth Jelin llamaríamos una lucha entre memorias $(2002,6)$. Es decir, una batalla entre las diversas historias, interpretaciones y justificaciones que surgen alrededor de un mismo pasado; un conflicto incesante entre las verdades del victimario que buscan imponerse y las de las víctimas que obstinadamente resisten. Al final de la pieza, después de un diálogo arduo, prolongado y doloroso, donde todos los personajes aprenden un poco sobre su propia naturaleza y los alcances de sus acciones, los Sosa logran su cometido: Salvo reconoce lo que ha hecho, confiesa dónde ha dejado los cuerpos y pide perdón.

Mi interés por esta pieza nace como resultado de mi actual investigación sobre las representaciones de la violencia paramilitar en la producción cultural colombiana del siglo XXI. Considero que esta obra es imprescindible para los estudios sobre teatro y memoria en Colombia por las relaciones que en ella se establecen entre humor y memoria, violencia y género, memoria y género, medios de comunicación y conflicto,
Venimos de la tierra y a ella volvemos desconocidos e irreconocibles y más que todo, olvidados. Sara Maneiro, La mueca de Berenice

El teatro alumbra allá donde nadie alumbra Cesar Badillo, ¿Qué pasaría si el río hablara?

animales y violencia o, incluso, selva y ciudad, por mencionar las más evidentes. Pero, sobre todo, por el momento coyuntural en el que se estrena, a saber, tres años después de que el gobierno de Juan Manuel Santos y las FARC firman en La Habana el Acuerdo general para la terminación del conflicto y la construcción de una paz estable y duradera, y un año antes de que se lleve a cabo el plebiscito sobre los acuerdos de paz.

Recordemos que el 26 de agosto del 2012 gobierno y FARC se comprometen a iniciar conversaciones directas e ininterrumpidas sobre una agenda entre cuyos puntos centrales están la participación política de excombatientes y las víctimas. ${ }^{2}$ Los diálogos traen esperanza a aquellos que ven en una negociación la única salida viable a más de medio siglo de guerras internas, pero a la vez suscitan preguntas y resistencias entre algunos grupos de víctimas, la población más conservadora y los partidos de derecha, en especial en lo referente a la amnistía y los pactos políticos que se van a alcanzar con la guerrilla.

Para calmar los ánimos, el gobierno promete refrendar los acuerdos finales a través de un plebiscito nacional. Esta promesa acrecienta la polarización del país y lo sume por años en una guerra mediática a favor y en contra de lo que se va a pactar en Cuba. Por un lado, en cabeza del Presidente Juan Manuel Santos y su Partido Social de Unidad Nacional se promueve la campaña por el sí. Con él están el Partido Liberal, Cambio Radical (una convención disidente del liberalismo), el Polo Democrático (el partido de izquierda más representativo del país) y una franja importante del Partido Conservador. Contra ellos, están los promotores del no, dirigidos por el expresidente Álvaro Uribe Vélez, su partido político: Centro Democrático y una disidencia del Partido Conservador, impulsada por el también expresidente Andrés Pastrana. ${ }^{3}$

Uno de los argumentos centrales de los opositores es que los acuerdos vulneran los derechos de las víctimas a la verdad, la justicia, la reparación y son una afrenta a su dolor. ${ }^{4}$ 
El gobierno se defiende recordando que hay un punto en la agenda dedicado exclusivamente a este asunto y que un grupo representativo de sesenta víctimas - divididas en cinco delegaciones - va a La Habana para formar parte de las conversaciones. ${ }^{5}$ Los críticos, frustrados por la evidente voluntad de reconciliación de la mayoría de los miembros de las delegaciones, optan por desvirtuar la condición de víctimas de los convocados.

La senadora por el Centro Democrático, María Fernanda Cabal, publica en Twitter una foto de Ángela María Giraldo - hermana de un diputado del Valle asesinado por las FARC tras cinco años en cautiverio-posando junto a un guerrillero. Al lado de la foto, la frase: "Esta 'víctima' saluda a las Farc muy contenta... ¿Síndrome de Estocolmo? [...] ¿Esa que saluda con una gran sonrisa a las Farc es representante de las víctimas?". ${ }^{6}$ Como este hay otros casos donde las víctimas que acompañan el proceso de paz son vituperadas, cuestionadas, juzgadas y hasta amenazadas por su voluntad de perdonar (Becerra 2007,3). Los efectos y alcances de esta guerra política y mediática se hacen evidentes el 2 de octubre del 2016 cuando gana la opción por el no y el 17 de junio del 2018 cuando Iván Duque Márquez, representante del Centro Democrático, gana la presidencia de la República. Resulta paradójico que quienes otrora contemplaron el diálogo como salida ideal al conflicto y camino seguro para garantizar la justicia de las víctimas se opongan tan vehementemente, alegando injusticia hacia las víctimas, al proceso de reconciliación con las FARC.

Labio de liebre, entonces, no solo surge en dicha coyuntura, sino que lo hace de cara a ella. La pieza medita sobre una pregunta concreta en un momento histórico específico: ¿perdón o venganza? Utilizo el verbo meditar para subrayar que si bien esta obra explora y reflexiona sobre nuestras nociones de víctima, victimario, justicia, reparación, empatía, etc., no lo hace con la intención didáctica de comunicar una moraleja o de dar una respuesta absoluta al interrogante que propone (Rubiano 2018). A este respecto, Rubiano ha repetido hasta el cansancio que lo suyo no es el teatro documental, político, testimonial o aleccionar y generar conciencia: "¿Cuál? ¿La conciencia de quién? ¿La mía? No. Nos sentimos incapaces siquiera de dar un consejo" (2018). Aún así, es difícil creer que el estreno de esta obra en dichos tiempos inextricables es arbitrario. Mucho menos si consideramos que Labio es coproducida por el Teatro Colón de Bogotá y estrenada en dicho recinto. Esto significa que la pieza ve la luz en un espacio gubernamental, emblemático, de élite, en el que la población urbana de clase media y alta accede tradicionalmente a la producción cultural que se presenta en la capital. Éste es un detalle esencial si se tiene en cuenta que, como se afirma en el informe ;Basta ya! del Centro de Memoria Histórica:

La guerra se ha librado mayoritariamente en el campo colombiano, en los caseríos, veredas y municipios, lejanos y apartados del país central o de las grandes ciudades. Es una guerra que muchos colombianos y colombianas no ven, no sienten, una guerra que no los amenaza. Una guerra de la que se tiene noticias a través del lente de los medios de comunicación, que sufren otros y que permite a miles de personas vivir en la ilusión de que el país goza de democracia plena y prosperidad, a la vez que les impide entender la suma importancia de cada decisión, afirmación o negociación política para quienes la sufren. $(\mathrm{CNMH}$ 2013, 22)

La particularidad de la pieza está, sin embargo, en que se ocupa de la dicotomía venganza o perdón no a través de la representación del proceso de paz con las FARC, sino del que se da entre el 2003 y el 2006 entre el gobierno de Álvaro Uribe Vélez y las Autodefensas Unidas de Colombia. Este proceso se inaugura con la firma en Santa Fe de Ralito (Córdoba) de un acuerdo de diez puntos, entre los cuales se adscribe el compromiso de las AUC a desmovilizar 34 bloques paramilitares y el del gobierno a adelantar las acciones necesarias para garantizar la reincorporación de los combatientes a la vida civil (“Acuerdo de Santa Fe" 2007).

Entre dichas acciones está la creación de un marco jurídico que regule el desarme, la desmovilización y la reincorporación de las AUC ("La desmovilización" 2008). Se aprueban, entonces, dos leyes fundamentales: la Ley 782 de 2002 o "Ley de Orden Público" y la Ley 975 de 2005, también conocida como "Ley de Justicia y Paz". La primera de esta leyes elimina el requisito estipulado en una ley anterior, la Ley 418 de 1997, según el cual es necesario reconocer estatus político a todo grupo armado con el que se establezcan diálogos (Grajales 2011, 166-172). Al eliminar este requisito, el gobierno evita en un primer momento el debate nacional en torno al reconocimiento político de las AUC, a la vez que garantiza la asignación de indultos a miembros de organizaciones armadas ilegales que no hayan incurrido en violaciones del derecho internacional humanitario (Grajales 2011, 166-167).

Como puede anticiparse, muchos paramilitares son acusados de cometer crímenes que caen, precisamente, bajo esta categoría. La Ley 975 surge, entonces, como respuesta a la necesidad de instituir un marco jurídico propicio para este tipo de infracciones (Gómez 2007, 80; Grajales 2011, 167). Más adelante volveré sobre esta ley, pues ocupa un lugar central en la trama de la pieza. Bástenos por ahora recordar que la desmovilización paramilitar concluyó en el 2006, no sin antes tomar una serie de giros inesperados cuando, primero, Carlos Castaño, fundador de las AUC, quizás el paramilitar más reconocido a nivel nacional e internacional y firmante del Acuerdo de Santa Fe, fue asesinado por orden de sus colegas Salvatore Mancuso, Jorge 40 y su hermano Vicente Castaño ("Confirmado: Carlos Castaño está muerto" 2006) - presuntamente por oponerse a la incorporación en los diálogos de jefes paramilitares de origen narcotraficante, 
como era el caso de Don Berna (Grajales 2011, 152). Segundo, cuando se destapan las relaciones de connivencia entre jefes paramilitares y políticos a nivel regional y nacional, en el denominado escándalo de la parapolítica (“¿Quiénes son los congresistas..." 2018). Y tercero, cuando en el 2005 el gobierno inicia, con Don Berna, una serie de extradiciones a Estados Unidos de los jefes paramilitares más importantes acusándolos de incumplir los acuerdos y continuar con sus actividades delictivas. Esto último, en detrimento de los procesos de verdad y reparación que benefician a las víctimas $\mathrm{y}$ a favor de los acusados, quienes terminan pagando condenas minúsculas en el país del norte (Sontang 2016).

Se pueden aventurar varias hipótesis sobre por qué Labio de Liebre trata el acuerdo con los paramilitares y no el de las FARC. Rubiano ha dicho que la idea de la obra surgió precisamente durante aquel proceso de paz, pero esto no explica la elección del momento del estreno seis años después (Oquendo 2015). Sospecho que la polémica inaugurada por el expresidente Uribe y sus aliados sobre lo injusto de los acuerdos $\mathrm{y}$, en general, sobre quién es y cómo deben comportarse las víctimas, influyó en el lanzamiento de la obra. En todo caso, incluso si esta suposición es errada, lo cierto es que Labio de liebre analiza, revisita y cuestiona las garantías de justicia que tuvieron las víctimas del paramilitarismo durante la desmovilización de las AUC, en un momento en el que esas mismas garantías estaban siendo utilizadas como excusa por los detractores del proceso de paz con las FARC.

Labio de liebre se desarrolla al interior de una diminuta casa. Inicia en medio de una oscuridad que solo es interrumpida por los destellos de un televisor encendido y por una luz opaca que entra tímidamente por una única ventana. Es de noche y la nieve que cae afuera delata un invierno interminable. Sentado en un sofá, Salvo Castelo se pasea incesantemente por canales de televisión en inglés y danés. Está en tierras extranjeras. De repente, la habitación se ilumina y se revela un recinto modesto que contiene en una misma área la sala, el comedor, la cama, la cocina y el baño. El rojo y el café- - los colores de la sangre y de la tierra — dominan el espacio y la vestimenta del hombre que lo habita. Salvo lleva puestos unos guantes de cuero rojos que nos recuerdan los guantes que usan los asesinos cuando no quieren dejar huella. El color de los guantes anuncia la mancha de la culpa.

Dos figuras disonantes hacen su aparición. Fuera de la casa, atraviesa frente a la ventana una liebre con características antropomórficas. Viste una ruana y usa botas de caucho. Parece estar buscando algo. ${ }^{8}$ Dentro, una mujer de origen campesino barre, organiza y existe en silencio, como si nadie notara su presencia. La liebre desaparece (o esa es la impresión del espectador) y, en su lugar, aparece un joven con vestimenta de invierno y labio leporino. ${ }^{9}$ Toca a la ventana, quiere entrar. El protagonista se reúsa. El joven insiste. Se llama Granado. Necesita hablarle con urgencia.
En este primer acto, la comodidad de Salvo contrasta con el desamparo del visitante. Pese a estar en un espacio pequeño, Castelo tiene acceso a un resguardo: una casa caliente que suple sus necesidades básicas. Granado, por su parte, tirita de frío al otro lado de las paredes. Para este momento de la obra, el espectador no sabe que la casa funge como cárcel y no tiene cómo adivinarlo: hay una ventana, una puerta, un televisor y un teléfono, todos estos puentes unen lo externo con lo interno y le permiten a Salvo cierta movilidad, al menos, mental. Hay una posición privilegiada que se evidencia en la posibilidad de estar recluido pero, a la vez, tener cierto acceso al mundo exterior. Granado, por el contrario, está a la intemperie en medio del invierno. De nada le sirve ser libre. La ventana y la puerta hacia el bienestar del interior de la casa están cerradas para él. La posibilidad de encontrar un abrigo depende, aparentemente, de la voluntad de Salvo.

La escena evidencia, además, el uso de la palabra como una prerrogativa. Granado no solo necesita un techo, viene en busca de un oído. Quiere hablar y ser escuchado, pero Castelo lo desprecia. La voz del privilegiado es la única que escuchamos. Al otro lado de la ventana las palabras de Granado son como pajaritos que se estrellan contra el vidrio. De la misma forma que es sentenciado a estar afuera, Granado es condenado al silencio. Salvo lo despide, le da la espalda y lo ignora. Este comienzo es determinante para entender el statu quo de la relación entre ambos individuos: tanto el bienestar del más débil como su posibilidad de hablar dependen de la voluntad del privilegiado. Identificar la estructura jerárquica con la que inicia la pieza y ser capaz de ver cómo dicha estructura reproduce la relación de la víctima del paramilitarismo con su victimario nos permite descubrir que en la obra se subvierte dicha jerarquía.

Asediado por el requerimiento obstinado de Granado, Salvo se da por vencido y deja entrar al visitante. El ingreso de Granado a la casa echa a correr la trama de la obra. Desde el principio, el joven interactúa de manera familiar con la mujer. La conoce. Le habla. Ella también le habla. Es en ese instante cuando descubrimos que esta mujer existía sin ser percibida, habitaba la casa de Salvo sin que este hubiera notado aún su presencia. Lo veía sin que él pudiera verla. Es un fantasma. También Granado lo es (pero para el espectador esto aún no resulta claro).

Mientras Granado explica a Salvo los efectos que su malformación produce en las personas que lo miran, aquel alterna la voz de adulto citadino con la de un niño campesino. De igual manera, sustituye paulatinamente su abrigo y botas de invierno por una ruana y unas botas de caucho. Salvo se da cuenta de los cambios, está sorprendido, pero pretende que nada sucede. Se marca así la relación ineludible entre fantasma y ruptura. La aparición de la figura espectral implica un quiebre, una fractura, en la realidad. Hay una linealidad temporal y discursiva que se interrumpe con la aparición del 
espectro. La discusión deriva rápidamente hasta el siguiente diálogo:

LA LIEBRE. ¿Por qué no me he operado?

SALVO. No sé por qué no se ha operado. [...]

LA LIEBRE. No me operé porque no crecí. [...]

LA LIEBRE. No crecí en la vida. No alcancé por ejemplo al tratamiento psicológico. (Ríe.) Dicen que uno se repone después de que ha sido víctima de un hecho atroz.

SALVO. "Víctima", "Hecho atroz..." Creo saber para donde va. Tal vez usted deba irse, señor.

LA LIEBRE. Discúlpeme, yo sé que el que está en proceso de recuperación es usted, pero es que esto es parte del proceso. Quiero ayudarlo. [...]

LA LIEBRE. Usted dijo que se acordaba...

SALVO. ¿De qué?

LA LIEBRE. De mi.

SALVO. Nunca lo había visto...

LA LIEBRE. Cuando era niño.

MADRE. Así, chiquito.

SALVO. Váyase

LA LIEBRE. Me mataron cuando era niño, y por eso no me operé. Aquí hay fundaciones que hacen la operación gratis. [...]

SALVO. vamos a dejar esto claro: yo estoy aquí pagando esta condena por algo que hice

LIEBRE Y MADRE. ¡Algo!

MADRE. Oigan a éste. Papito, acérquesele, cuéntele.

LA LIEBRE. "Algo", no, señor (Le aclara.) Me mató señor, usted. Usted me mató. Es decir, no me mató. Cuando me enterró estaba medio muerto, no muerto por completo. (Rubiano 2015a, 10-12)

De esta forma descubrimos que Castelo ha asesinado a ese hombre, que es en realidad un niño de siete años. También ha asesinado a su familia, compuesta por Alegría de Sosa, la mujer que hemos visto desde el principio, y dos hermanos mayores que no tardan en aparecer en escena: Jerónimo de nueve años y la adolescente Marinda (con quien el asesino tuvo un romance y a la que ultimó por haber abortado un hijo de ambos). Ahora que Castelo se encuentra en tierras lejanas pagando por sus crímenes, los Sosa vienen a su encuentro. No quieren venganza, aunque su presencia signifique un gran tormento para su victimario, quieren que él haga memoria, que los reconozca, y por ello vienen a ayudarlo a recordar.

Durante estos primeros minutos de la obra, la palabra "paramilitar" no es utilizada (jamás la escucharemos), pero hay al menos tres elementos que nos permiten reconocer poco a poco quién es nuestro victimario y de qué tipo de violencia se ocupa Labio de liebre. Primero, están el nombre de origen italiano del protagonista, que evoca al del jefe paramilitar Salvatore Mancuso, así como una referencia textual posterior a algunos extractos de la alocución de este último ante el Congreso de la República el 28 de junio del 2004. ${ }^{10}$ Segundo, la condición rural de las víctimas y el hecho de que fueron asesinadas en una masacre nos remiten a un modus operandi, compartido por todos los actores del conflicto, pero connatural a los paramilitares. ${ }^{11}$ Tercero, la referencia a un proceso legal que intercambia beneficios jurídicos (como una condena mínima) por confesiones. En un diálogo posterior entre los Sosa y Castelo se explicita esta referencia:

MADRE. Sumercé no nos ha entendido. Nosotros vinimos acá fue a presentarnos.

LIEBRE. Para que de verdad nunca se le vayan a olvidar cómo llaman nuestros nombres.

MADRE. Vea, mi nombre llama Alegría de Sosa.

HERMANO. Jerónimo Sosa.

LIEBRE. Granado Sosa.

MALA. Marinda Sosa. [...]

MADRE. Es que Don Salvo se acuerda de lo que hizo pero no a quiénes personas.

SALVO. ¿Para qué quieren que me aprenda sus nombres?

HERMANO. Pues para que los diga allá.

SALVO. Allá, ya di suficientes nombres.

MADRE. No los nuestros. ¿Dónde está Marinda, Jerónimo, Granado, Alegría?

SALVO. ¡No voy a dar más nombres para que me abran un nuevo proceso, me tengan un año más en este cagadero, y pierda todos los beneficios! 
MADRE. Si sumercé sigue tan insistido en eso, entonces aquí nos quedamos a vivir con usted.

(Rubiano 2015a, 46-47)

La alusión a la mencionada Ley 975 de 2005 o "Ley de Justicia y Paz", creada durante el proceso de desmovilización de las AUC para "facilitar [...] la reincorporación a la vida civil de grupos armados al margen de la ley", es innegable. Según esta ley, quienes contribuyan con el esclarecimiento de la verdad y la reparación económica de las víctimas, y favorezcan su resocialización a través del trabajo, estudio o enseñanza, pasarán privados de la libertad un máximo de ocho años. ${ }^{12}$ La ley, sin embargo, no es polémica solo por la extensión irrisoria de las penas. Para sus detractores, la mayor falencia de "Justicia y Paz" está en que considera a las víctimas de un modo muy limitado. No da un lugar privilegiado a las narrativas que éstas han creado en torno al conflicto o sus propias vivencias, sino que restringe sus discursos a la enunciación de los detalles que contribuyen exclusivamente a las pesquisas forenses o a la formulación de preguntas y contra-preguntas "apropiadas" durante las versiones libres. ${ }^{13}$

Además de lo anterior, la Ley 975 da prioridad a la verdad procesal sobre la verdad histórica y, bajo este criterio, tiende a considerar el testimonio de las víctimas "marginal y de menor "efecto de verdad" que el del victimario" (Aranguren 2012, 20). Como resultado, en muchos casos las versiones de los paramilitares terminaron desmitificando las versiones marginales sobre la violencia (Aranguren 2012, 20). Una muestra de esta conducta se vivió en la segunda sesión de versión libre de 'El Loro,' donde el Fiscal de Justicia y Paz interrumpió la lectura de una pregunta formulada desde la sala alterna por el familiar de una víctima por tratarse de sucesos acaecidos en una zona en la que el paramilitar dijo no haber estado (Becerra 2007, 2). Esta fue la forma en que la ley contribuyó a reforzar una dinámica mediática que, desde hacía mucho tiempo, difundía irrestrictamente la voz y la verdad del victimario, a la vez que restringía, desvirtuaba o minimizaba el testimonio de la víctima (García 2013, 19).

A la luz de esta información es posible entender por qué Labio de liebre se desarrolla en tierras extranjeras, a qué tipo de proceso legal está vinculado Salvo y, sobre todo, por qué son los Sosa los que van a su encuentro. El reclamo de la familia a Salvo por no haber dicho sus nombres "allá," o que este confiese no haberlos dicho por temor a perder beneficios judiciales, son todos elementos que evidencian la insuficiencia del escenario judicial para garantizar la verdad, la justicia y la reparación demandada. No son posibles la verdad y la reparación allí donde el único que habla es el victimario, y cuando este dice solo lo que él (y no las víctimas) considera suficiente. Por ello, en la obra la víctima es la que tiene la palabra, la que confronta sin temor a su asesino, la que exige que se le escuche y persiste con éxito en su búsqueda de la verdad.
El recurso que hace posible esta subversión de las dinámicas de jerarquía y privilegio es la figura del fantasma. Valiéndose del espectro, Rubiano enfrenta una dupla improbable: el asesino y el testigo integral. Éste es - para usar los términos de Agamben-, la víctima que ha padecido hasta las últimas consecuencias una experiencia violenta y, por lo tanto, no ha sobrevivido para dar testimonio $(2009,18)$. Contra todo pronóstico, gracias al fantasma, el testigo integral tiene la posibilidad de testimoniar, de narrar su verdad sin que su voz pueda ser silenciada, ignorada o descartada. El asesino que amedrenta bajo la amenaza de quitar la vida, pierde todo poder de chantaje frente a este no-vivo que ahora reclama lo que es justo:

MADRE. No, Don Salvo. Nosotros vinimos aquí a que sumercé nos conociera y se aprenda los nuestros nombres. [...]

MADRE. Shht. Y para que nos reconozca. [...]

MADRE. Y otra cosa, don Salvo. Nos vamos a quedar acá a vivir con sumercé, hasta que usted se dé cuenta que somos una familia de bien, así como la suya de sumercé.

SALVO. ¿Mi familia? Si algo le llega a pasar a algún miembro de mi familia, les va a ir peor de lo que ya les ha ido.

MARINDA. Uy, ¡tan bravo y tan miedoso!

LIEBRE. ¿Qué, nos va a rematar?

HERMANO. ¿O a contramatar?

(Rubiano 2015a, 46)

Lo paradójico es que la relación entre fantasma y verdad es en sí problemática. Ya en El sofista, Platón había asociado el fantasma con el no-ser y, por lo tanto, con lo opuesto de la verdad, al determinar que el fantasma era un simulacro de la realidad del que no se podía decir siquiera que era una copia fiel (236b): ¿cómo saber, pues, si lo que asecha al victimario es verdadero?, ¿cómo establecer si es una ausencia que efectivamente se ha hecho presente o la alucinación de una mente que desvaría en medio de la soledad? y ¿qué es exactamente lo que ha aparecido frente al protagonista?: ¿fantasmas?, ¿su pasado?, ¿sus culpas?, ¿sus miedos?, o ¿la locura? Y si la obra presenta no un diálogo entre un victimario y sus víctimas, sino un monólogo, ¿cómo podríamos afirmar que la verdad que se impone es la de la víctima y no otra acomodada versión de la verdad del victimario? Quizás habría que hacerse aún otra pregunta ¿por qué aborda Labio de liebre el tema de la verdad valiéndose de un recurso que problematiza la noción misma de verdad? 
En una conferencia de 1993 que después se volvió libro, Espectros de Marx. El estado de la deuda el trabajo del duelo y la nueva internacional, Jaques Derrida analiza lo que ha significado para su generación el pensamiento de Marx. Su trabajo es una revisión de los alcances de la presencia de cierto "espíritu del marxismo" en los albores del siglo XX (Sprinker 2002; Rocha 2010). Y si bien su intención con aquella conferencia era responder a la pregunta para la cual había sido convocado: "¿A dónde va el marxismo?," las reflexiones que allí desarrolló en torno al espectro fueron reveladoras para los estudios culturales sobre memoria y fantasma. Con Derrida, el fantasma devino espectro, se liberó de ser el cliché de las narrativas de suspenso y se volvió una metáfora conceptual y una herramienta analítica que sirve para pensar las irrupciones del pasado en el presente, la memoria y las ausencias (Blanco y Peeren 2013, 1).

En aquel texto, el filósofo francés afirma, refiriéndose al espectro: "no se sabe lo que es, [...] Es algo que, justamente, no se sabe, y no se sabe si precisamente es, si existe, si responde a algún nombre y corresponde a alguna esencia. No se sabe: no por ignorancia, sino porque ese no-objeto, ese presente no presente, ese ser-ahí de un ausente o de un desaparecido no depende ya del saber" $(2012,20$; énfasis en el original). Es por esta inaprehensibilidad que resulta infructuoso que el victimario de Labio de liebre se pregunte por la realidad de las entidades que lo asechan (porque, reales o no, le es imposible evadirlas). De la misma manera, es en vano que el espectador de la obra se pregunta si la imagen espectral que presenta Rubiano se da exclusivamente en la cabeza del victimario o si sucede en la realidad, si se trata de un monólogo o de un diálogo, porque el espectro demanda - tanto dentro como fuera de la obra - no ser ya interrogado desde la sospecha que despierta el escepticismo epistemológico, sino nuestra absoluta rendición ante él. "Sumisión esencialmente ciega a su secreto, al secreto de su origen: primera obediencia a la inyunción, que condicionará a todas las demás" (Derrida 2012, 21).

Esta rendición se da a propósito de lo que Derrida denomina "efecto visera" (Derrida 2012, 21): el espectro tiene el poder que otorga la capacidad de mirar sin ser mirado, mientras que el otro no-espectral está condenado a no ver a quien lo mira (Derrida 2012, 21). En una entrevista con Bernard Stiegler titulada Spectrographies (2002), Derrida explica este "efecto visera" de la siguiente manera: "The specter is not simply this visible invisible that I can see, it is someone who watches or concerns me without any possible reciprocity, and who therefore makes the law when I am blind, blind by situation. The specter enjoys the right of absolute inspection. He is the right of inspection itself" (121). La superioridad del espectro reside, pues, en esta doble incapacidad que tiene el otro no-espectral de, primero, verlo y, por lo tanto, anticiparlo y evadirlo, y, segundo, de conocerlo y, como resultado, de fijarlo, atraparlo o encuadrarlo (Rocha 2010, 76).
En Labio de liebre este "efecto visera" es claro desde el principio. Recordemos la escena inicial: Alegría de Sosa barre y organiza la casa sin que Salvo la note. Ella cohabita con él sin que él sepa o pueda tener control sobre su presencia en la morada. De hecho, es ella la que determina cuándo es el momento adecuando para hacerse visible. Pensemos, ahora, en la aparición de Granado. Él no está dentro de la casa, pero tan pronto entra a la vivienda el diálogo comienza inexcusablemente. Su urgencia de hablar es superior a la capacidad de Salvo para repelerlo. Una vez la condición espectral de Granado se hace patente, son fútiles los esfuerzos de Castelo por frenar el diálogo que ha iniciado el fantasma. El llamado del espectro es ineluctable. Al final, la única salida-como indica Derrida - es rendirse ante él.

Hay algo más. El espectro, como lo mencionamos anteriormente, implica la ruptura de cierta lógica de lo real, una alteración del orden convencional. En términos del problema de la verdad, lo que se fractura con la aparición del fantasma es la hegemonía del discurso que representa Castelo. En otras palabras, la irrupción de la voz espectral, de sus demandas, quiebra el discurso dominante del victimario. De ahí que Rubiano se valga de una imagen tan disonante con la idea de verdad para tratar, precisamente, el problema de la verdad. La figura espectral dinamita el orden del discurso establecido para que, de esta forma, otros discursos puedan ser enunciados.

Hay una serie de momentos en la obra en los que se evidencia esta fractura. Por ejemplo, cuando Granado confronta a Salvo y le recuerda que él es su asesino: "Me mató señor, usted. Usted me mató" (Rubiano 2015a, 10-12); cuando Granado desmiente las afirmaciones de Salvo según las cuales no sabe quién es; cuando Jerónimo le recuerda a su victimario que sus hombres le cortaron la cabeza y jugaron fútbol con ella (Rubiano 2015a, 28-30) o, finalmente, cuando Salvo, presionado, reconoce que acordarse de los Sosa implicaría perder los beneficios que le ha otorgado la ley (Rubiano 2015a, 46-47). ${ }^{14}$ En todos estos momentos, cuando los dialogantes alcanzan la verdad, el escenario se oscurece y una luz blanca ilumina sus rostros.

El contraste entre oscuridad y luz en el marco de esta lucha de memorias da cuenta de la oscuridad que produce el olvido sistemático y de cómo esta oscuridad solo puede ser resistida por la luz que se produce en el diálogo ${ }^{15}$ En este punto es casi imposible - guardando las justas proporciones - no pensar en Platón; no ya a propósito de la naturaleza no-real del fantasma, sino del diálogo como condición de posibilidad para acceder a la verdad. En un texto de Humberto Giannini sobre la relación entre diálogo y verdad en Platón se afirma: "[s]in corresponder en absoluto a un valor relativo, la verdad es un acontecimiento que implica participación. En otras palabras: el camino hacia el ser real y hacia la verdad pasan necesariamente al través de una conciencia dialogante" (2004, 189-90; 
énfasis en el original). Es decir, en el diálogo se hace evidente el carácter intersubjetivo de la verdad (González, n.d.).

En los estudios contemporáneos, la compleja relación entre memoria y verdad se hace cuerpo en la noción de testigo. Primo Levi inicia el primer capítulo de Los hundidos y los salvados afirmando "La memoria humana es un instrumento maravilloso, pero falaz" $(2015,485)$. Con esta frase el autor busca evidenciar la profunda paradoja que enfrenta todo testigo: el recuerdo de un evento puede ser la única prueba que tenemos de su existencia real, pero todo recuerdo es susceptible de ser falseado. "Es una verdad sabida," dice Levi, que "[1]os recuerdos que en nosotros yacen no están grabados sobre piedra; no sólo tienden a borrarse con los años sino que, con frecuencia, se modifican o incluso aumentan literalmente, incorporando facetas extrañas" $(2015,485)$. Los motivos de esta falsificación pueden ser todos, desde evitar un dolor profundo hasta evadir la responsabilidad de una acción (como en el caso de Salvo). Lo cierto, sin embargo, es que toda memoria es, de suyo, una reconstrucción más que un recuerdo (Jelin 2002, 21).

El relato de nuestro pasado exige una constante selección, consciente o inconsciente, de unas imágenes sobre otras, de unas experiencias sobre otras. Así, en la construcción de la memoria, necesariamente algunos eventos del pasado o rasgos de estos eventos serán conservados mientras que otros serán marginados y luego olvidados (Todorov 2008, 22). En su obra El olvido que seremos, Héctor Abad Faciolince lo expresa de la siguiente manera: "lo ya ocurrido y lo que está por venir, en mi cabeza, son apenas conjeturas. Los relatos autobiográficos $[\ldots]$ tienen esa consistencia $[\ldots]$ la paciente reconstrucción por indicios de un pasado que ya no se recuerda bien" (Abad Faciolince 2009, 11-12).

Reconocer que esta es la naturaleza de la memoria está lejos de significar que toda versión del pasado es verdadera o que la verdad es relativa, pero sí nos ayuda a entender que "una aproximación a la precaria verdad humana se construye solamente con la suma de los recuerdos imprecisos, unidos a la resta de los distintos olvidos" (Abad Faciolince 2009, 114). En otras palabras, que "[1]a verdad suele ser confusa; [y] es la mentira la que tiene siempre los contornos demasiado nítidos" (Abad Faciolince 2009,148). En un artículo titulado "Testimonies of Repression. Methodological and Political Issues," Jo Labanyi, consciente de esta paradoja, afirma que el valor primordial del testimonio no está tanto en su capacidad para establecer con absoluta claridad y certeza qué fue lo que pasó (aunque esto debe suceder), como en presentarnos las actitudes emocionales de quien testimonia en el momento en que habla $(2010,193)$. Labanyi aboga, de esta manera, por un desplazamiento de lo epistemológico a lo emocional que se traduzca en una actitud más empática y menos inquisitiva hacia quien nos habla. "I am arguing for a view of testimonio not so much as a "politics of truth" (Beverley's definition), but rather as a "politics of feeling" $(2010,204)$.
También en Labio de liebre la verdad se alcanza a través del diálogo. Pero esta verdad no nos remite ya a la mera conformidad entre narración y hecho, sino a la capacidad de ponerse en el lugar del otro. Es aquí donde la mirada de Labanyi resulta iluminadora. Durante el acto tercero, en lo que puede ser descrito como un juego de cambio de roles, víctimas y victimario intercambian lugares y recrean la masacre:

SALVO. Hace unos meses tenía relevancia política, poder popular, apoyo de columnistas, de ganaderos, de industriales; decido aceptar la condena, acogerme, llego aquí, y empiezo a escuchar voces, a encontrar partes de cuerpos, muertos que se me aparecen.

MADRE. Nos podríamos ir.

SALVO. Váyanse.

MADRE. Dígales nuestros nombres.

SALVO. No puedo.

MADRE. Entonces nos vamos a quedar aquí. [...]

MALA. (Calzada con los zapatos talla 49 de Salvo) Mamá, ¡mire, mire!

MALA. (A Salvo) Vea, me puse en sus zapatos. ¿Cómo me los ve o qué? Ay oye, ponte en los míos, ¿sí?

MADRE. (Quitándose los de ella) Pruebe usted con los míos. (Se los pasa a Salvo)

LIEBRE. ¿Será que sí cabe en los míos?

HERMANO. Y los míos.

MADRE. Póngase en nuestros zapatos [...]

SALVO. ¿Qué quieren que haga?

MADRE. Lo que hizo.

HERMANO. Haga memoria.

LIEBRE. Nos puso en fila. ¿Se acuerda de que yo llegué primero?

MADRE ¡Y el miedo!

SALVO. No quiero hacer eso.

MADRE. Pero lo hizo.

SALVO. No lo voy a hacer otra vez. 
LIEBRE. Es jugando.

MALA. Hágalo.

MADRE. ¿O prefiere estar a este lado?

SALVO. No.

MADRE. Comencemos.

SALVO. ¿Por dónde?

HERMANO. Pues por la fila. [...]

SALVO. (Comienza la representación. Sin convicción) Se me colocan en una fila aquí me hacen el favor. ¿Así?

HERMANO. Noooo, su voz hablaba más fuerte.

MADRE. Sumercé estaba gritando. ¡Grite! ¿O es que ahora no puede?

SALVO. (Obedece) ¡Se me colocan en una fila aquí me hacen el favor!

MADRE. Ahí comenzamos a gritar.

(Rubiano 2015a, 59-62)

El juego-esta suerte de teatro dentro del teatro-termina con un Salvo que empieza a reconocer lo que hizo. Un Salvo conmovido, no porque haya sido confrontado con una verdad, sino porque este diálogo didáctico le ha permitido experimentar las emociones de los otros, y vivir como suyas por un momento esas emociones:

SALVO: ¿Ustedes sentían este miedo?

MADRE: ¿Lo siente?

SALVO: Sí.

Y la culpa...

MADRE: ¿También la siente?

SALVO: ¡Que sí!

(Rubiano 2015a, 70)

Esta conmoción arroja luces sobre otro tipo de diálogo: el que se da entre obra y público. En Labio de liebre no hay un diálogo directo con el espectador. Esta no es una pieza que involucre activamente al público. Con todo, es innegable que quien la observa se siente indefectiblemente interpelado. No solo porque habla de una violencia que resulta familiar, sino porque goza de la fuerza y la contundencia que produce el hecho de que dicha violencia está sucediendo ante nuestros ojos: "no me interesa que el teatro de respuestas [...] ni que dé consejos [...] pero sí me interesa hacer preguntas acerca de una fractura social que vive este país" (Rubiano 2014). Así, de la misma manera que la actuación de los Sosa produce ciertos efectos en Salvo, la obra tiene efectos sobre el espectador. De ahí las palabras del dramaturgo y actor César Badillo cuando le preguntan cuál es la función del teatro en una sociedad en conflicto permanente:

Es claro que el teatro no para guerras, ni quita el hambre. En cambio es una vía de conocimiento, de hacerse preguntas, de poner a pensar a seres sensibles, de circular ideas insólitas y ampliar la mirada sobre el problema, de alumbrar allá donde nadie alumbra. Con dos o tres personas que salgan tocadas, que se hayan divertido y que salgan conmovidas, eso ya es suficiente. (Badillo 2015)

Me gustaría concluir este texto volviendo sobre la figura del fantasma. ${ }^{16}$ Ya hemos afirmado que el espectro es la herramienta a través de la cual Rubiano subvierte las dinámicas perversas entre víctimas y victimarios que alimenta la Ley de "Justicia y Paz". Pero lo cierto es que el espectro es una metáfora rica en posibilidades. Una de estas posibilidades consiste en entender el fantasma como el mecanismo a través del cual una ausencia se hace presente. Y, en este sentido, el espectro habla, a su vez, del valor que tiene esta obra en particular, y el teatro en general, como medio a través del cual se puede comprender el conflicto colombiano. La labor del teatro en relación con la violencia es que recrea, es decir, pone en escena, a través de la presencia del cuerpo, la violencia que está ausente. Y ésta está ausente ya sea o porque es violencia del pasado o porque es violencia que se experimentó en geografías ajenas a las ciudades. En Labio de liebre la imagen espectral le permite a Rubiano hacer presente algo que está ausente. Hacer visible algo que por su condición es invisible. Así, los Sosa no solo son reflejos de esa violencia rural y, en este sentido, no solo informan y recuerdan al espectador (que no es otro que el hombre de cuidad) los dramas que vive el campo, sino que también son la figura a través de la cual se le da de nuevo "vida" (y por "vida" entiendo voz y voluntad) a los muertos de la guerra. Y no solo voz, sino además cuerpo. Recordemos que los Sosa demandan que Castello revele dónde ha dejado sus cuerpos. El fantasma exige la aparición de su cuerpo, a la vez que él representa un aparecer virtual de esa corporeidad perdida. En efecto, Rubiano trae a escena no sombras, no sonidos, no entidades amorfas, sino cuerpos definidos. Incluso, acentúa esta corporeidad a través del tacto. En esta obra el protagonista está en contacto físico con los cuerpos que en realidad no están. Hay abrazos, besos, intercambio de vestimenta, contacto físico. En una frase: en Labio de liebre Rubiano aparece virtualmente los cuerpos desaparecidos. 
Finalmente, estos espectros revelan una ausencia mayor. Una que se hace patente a través de las siguientes preguntas: Y si los Sosa no hubieran vuelto como imágenes espectrales, ¿quién habría dado la pelea que ellos dieron? y ¿quién habría abogado para que sus nombres no se olvidaran y sus cuerpos no quedaran desaparecidos? Si hay algo que queda claro en la obra es que el Estado es incapaz de garantizar esta justicia. Aunque Salvo está pagando por sus crímenes, los tres años de condena son insuficientes, pero además es evidente que no está pagando por todos sus crímenes. Los nombres de los Sosa no aparecen en las listas que confesó. De cualquier forma, en el mejor de los casos, la ley garantiza una justicia procesal, pero la necesidad de los Sosa va más allá de estas garantías jurídicas. Su súplica es moral. Ellos requieren que sus nombres no sean olvidados, y este deseo supera el mero gesto del registro jurídico. Su clamor revela la ausencia y a la vez la necesidad de una comunidad de recuerdo.

\section{Obras Citadas}

Abad Faciolince, Héctor. 2009. El olvido que seremos. Bogotá: Planeta.

"Acuerdo de Santa Fe de Ralito para contribuir a la paz de Colombia." 2007. Bogotá: Alto Comisionado para la Paz. https:// web.archive.org/web/20070617024900/http://www.altocomisionadoparalapaz.gov.co/acuerdos/acuerdos_t/jul_15_03.htm

Agamben, Giorgio. 2009. Lo que queda de Auschwitz. El archivo y el testigo. Valencia: Pre-textos.

Aranguren, Juan Pablo. 2012. La gestión del testimonio y la administración de las víctimas: el escenario transicional en Colombia durante la ley de justicia y paz. Bogotá: Siglo del Hombre Editores.

Badillo, César. 2015. “QQué pasaría si el río hablara?” Entrevistado por Esteban Montaño. ¡Pacifista!, abril 5. http://pacifista.co/ que-pasaria-si-el-rio-hablara/

Becerra, Carmen. 2007. "Las versiones libres de los paramilitares y los derechos de las víctimas en la Ley 975 de 2005." Colectivo de Abogados “José Alvear Restrepo", abril 19. https://www.colectivodeabogados.org/LAS-VERSIONESLIBRES-DE-LOS

Blanco, María del Pilar y Esther Peeren. 2013. "Introduction.” En The Spectralities Reader. Ghosts and Haunting in Contemporary Cultural Theory, editado por María del Pilar Blanco y Esther Peeren, 1-27. New York: Bloomsbury.

Centro Nacional de Memoria Histórica (CNMH). 2013. ;Basta ya! Colombia: memorias de guerra y dignidad. Bogotá: Imprenta Nacional.

2009. La masacre de El Salado. Esa guerra no era nuestra. Bogotá: Imprenta Nacional.

“Confirmado: Carlos Castaño está muerto.” 2006. Semana , agosto 23, 2006. https://www.semana.com/on-line/articulo/ confirmado-carlos-castano-esta-muerto/80598-3

Derrida, Jacques. (1993) 2012. Espectros de Marx. El estado de la deuda, el trabajo del duelo y la nueva internacional. Madrid: Trotta.

Derrida, Jacques y Bernard Stiegler. 2013. "Spectrographies." En The Spectralities Reader. Ghosts and Haunting in Contemporary Cultural Theory, editado por María del Pilar Blanco y Esther Peeren, 37-51. New York: Bloomsbury.

García, Alexandra Isabel. 2013. "The Texture of Ideology: Demonstrating Bias in the Representation of the Internal Conflict in the Colombian Press." PhD diss., Australia Macquarie University.

Giannini, Humberto. 2004. La “reflexión” cotidiana. Hacia una arqueología de la experiencia. Santiago de Chile: Editorial Universitaria.

Gómez, Bersarión. 2007. “Análisis jurídico y constitucional de la Ley de Justicia y Paz (Ley 975 de 2005).” Revista Diálogos de Saberes, no. 27 (julio-diciembre): 73-100. 
González, Mauricio. n.d. "Diálogo y Filosofía.” En Akademos. http://www.galeon.com/filoesp/Akademos/colabora/fmg_dial. htm

Grajales, Jacobo. 2011. "El proceso de desmovilización de los paramilitares en Colombia: entre lo político y lo judicial." Desafios 23 (II): 149-194.

Jelin, Elizabeth. 2002. Los trabajos de la memoria. Madrid: Siglo XXI.

Labanyi, Jo. 2010. “Testimonies of Repression. Methodological and Political Issues.” En Unearthing Franco's Legacy. Mass Graves the Recovery of Historical Memory in Spain, editado por Carlos Jeres-Farrán y Samuel Amago, 192-205. Indiana: University of Notre Dame Press.

"La desmovilización: el proceso de paz (2003-2006).”. 2008. Verdad Abierta, 11 febrero, 2008. https://verdadabierta.com/ periodo4

Levi, Primo. 2015. Los hundidos y los salvados. Barcelona: Península

Oquendo, Catalina. 2015. "Se estrena 'Labio de liebre', mirada de Fabio Rubiano sobre víctimas." El Tiempo, 4 de marzo, 2015. https://www.eltiempo.com/archivo/documento/CMS-15341318

Platón. 1988. Sofista. Diálogos V, 319-482. Madrid: Gredos.

“¿Quiénes son los congresistas condenados por paramilitarismo?” 2018. El Espectador, julio 1, 2018. https://www.youtube. $\mathrm{com} /$ watch?v=hj0yKRnq_zc

Rocha, Delmiro. 2010. “La imagen y el fantasma.” Escritura e Imagen, vol. 6: 73-85.

Rubiano, Fabio. 2015a. Labio de liebre. Inédita.

_ 2015b. "Fabio Rubiano habla de Labio de liebre." Entrevistado por Yhonatan Loaiza. El Tiempo, mayo 29, 2015. https:// www.youtube.com/watch?v=6aO7nQDV4aM.

—. 2014. "No me interesa que el teatro dé respuestas." Entrevistado por Santiago Rivas. En Órbita, noviembre 7, 2014. https://www.youtube.com/watch?v=4GxRKuIuuJE.

—. 2018. "Nuestro teatro no está para dar clases de Historia, ni de ética: Fabio Rubiano." Entrevistado por Tania Tapia Jáuregui. Vice, marzo 14, 2018. https://www.vice.com/es_co/article/evmjz7/nuestro-teatro-no-esta-para-dar-claseshistoria-etica-fabio-rubiano-petra-labio-liebre

Sontang, Deborah. 2016. "Justicia interrumpida: Paramilitares en Colombia, presos privilegiados en Estados Unidos." New York Times, 9 de septiembre, 2016. https://www.nytimes.com/es/2016/09/09/paramilitares-colombia-narcotraficouribe-violencia-justicia-paz/?smid $=$ tw-share-es\&action $=$ click\&contentCollection=Americas\&module=RelatedCovera ge\&region $=$ EndOfArticle\&pgtype $=$ article

Sprinker, Michael. 2002. "Introducción.” En Demarcaciones espectrales. En torno a Espectros de Marx de Jacques Derrida, editado por Michael Sprinker, 7-10. Madrid: AKAL.

Todorov, Tzvetan. 2000. Los abusos de la memoria, Barcelona: Paidós.

\section{NOTAS}

1. Los diálogos que aquí se encuentran son, sin embargo, citas del texto inédito que Rubiano me facilita posteriormente. Agradezco al autor su generosidad al compartir ambos materiales conmigo. Estudiar la producción cultural colombiana contemporánea cuando se vive fuera del país es una tarea que de no ser por este tipo de gestos resulta inviable. 
2. Revisar el "Acuerdo general para la terminación del conflicto y la construcción de una paz estable y duradera." 2012. Bogotá: Alto Comisionado para la Paz. http:/www.altocomisionadoparalapaz.gov.co/procesos-y-conversaciones/acuerdo-general/ Documentos\%20compartidos/Acuerdo_General_para_la_terminacion_del_conflicto.pdf.

3. Ver el artículo "La mayoría de partidos saldrá a defender el 'Sí' en el plebiscito." 2016. El Tiempo, 2 de agosto. https://www. eltiempo.com/archivo/documento/CMS-16662673.

4. Ver el artículo "La verdadera paz empieza con el No.” Publicado por el actual presidente de Colombia, Iván Duque Márquez, Carlos Holmes y Óscar Iván Zuluaga en El Tiempo, el 27 de agosto del 2016. http://www.eltiempo.com/archivo/documento/ CMS-16684980.

5. Ver "Primera delegación de víctimas viaja a La Habana a encuentro con la Mesa de Conversaciones." Programa de las Naciones Unidas para el Desarrollo, agosto 15, 2014. http://www.co.undp.org/content/colombia/es/home/presscenter/articles/2014/08/15/primera-delegaci-n-de-v-ctimas-viaja-a-la-habana-a-encuentro-con-la-mesa-de-conversaciones-.html

6. Debido a la polémica que suscitó, el trino fue borrado. Hay, sin embargo, múltiples referencias a él. Ver, por ejemplo, el artículo "En medio de señalamientos, víctimas se ratifican en la reconciliación," publicado por El Tiempo el 20 de agosto de 2014. http://www.eltiempo.com/archivo/documento/CMS-14414099.

7. Recordemos que Pastrana fue artífice de los diálogos fallidos con las FARC en 1999 y que fue bajo el gobierno de Álvaro Uribe Vélez que las Autodefensas Unidas de Colombia negociaron su desmovilización en el 2003.

8. La presencia de animales antropomorfizados es un signo distintivo del trabajo de Rubiano. En Mosca, estrenada en el 2002 en el marco de las infructuosas negociaciones de paz entre el gobierno del presidente Pastrana y las FARC, desde el título hasta el personaje de Ganso Avestruz, nos hablan de un universo animal que se mezcla y padece la violencia humana: "Los animales $[\ldots]$ generan una distancia [...] siempre me sirven como metáfora, siempre me sirven para detectar elementos que no puedo detectar en la vida real. Y, sobre todo, para hablar de ciertas cosas que, si uno habla señalando a los humanos, pueden sonar raro" (Rubiano 2015b).

9. Labio de liebre es el nombre que, según la obra, se le da a las personas con labio leporino. La liebre que vemos al inicio de la obra es Granado, que en el texto teatral es llamado Liebre.

10. En el marco de las conversaciones de paz entre el gobierno de Álvaro Uribe Vélez y las AUC, tres de los principales jefes paramilitares: Salvatore Mancuso, Ramón Isaza y 'Ernesto Báez,' asistieron al Congreso de la República y hablaron, no solo ante los senadores, sino ante aquellos colombianos que sintonizaron su alocución a través del canal institucional. En un artículo de opinión titulado "Paras en el Congreso," el escritor colombiano Héctor Abad Faciolince llama la atención sobre el carácter de los discursos: "Salvatore Mancuso, en tono enérgico y reposado, leyó su arenga: 46 minutos y 15 segundos. Un largo ataque al abandono del Estado y una oda al heroísmo de las autodefensas. Con un par de excepciones (el senador Pardo y la representante Parody), los casi 60 congresistas presentes en la sesión (de un total de 268, hay que decirlo), además del gobernador de Córdoba y el alcalde de Montería, ovacionaron al comandante" https:/www.semana.com/portada/articulo/ paras-congreso/67269-3. Abad retoma una crítica harto conocida: los paramilitares fueron favorecidos, antes y después de la desmovilización, con una política gubernamental y mediática de micrófono abierto que les permitió justificar, sin ningún tipo de contra-discurso, sus acciones (CNMH 2009,109). En Labio de liebre, Rubiano toma fragmentos reales de dicha alocución, a la vez que recrea y ridiculiza el tono solemne de la misma. Mientras Salvo habla sobre su condición de héroe y mártir de la patria, los Sosa, que ven la transmisión a través del televisor, remedan las palabras de su victimario, como quien recrea un sonsonete carente de sentido y valor. Ver el discurso de Mancuso: Mancuso, Salvatore. 2004. "Discurso ante el Congreso de la República." Télam. Agencia Nacional de noticias, julio 28, 2014. http://www.telam.com.ar/advf/documentos/2013/11/52966a9d7950c.pdf.

11. Según establece el Grupo de Memoria Histórica (GMH) en su informe ;Basta ya!, en Colombia todos los actores armadoses decir, guerrillas, paramilitares, Fuerza Pública y grupos no identificados - han incorporado el ataque a la población civil como parte de su estrategia de guerra. Sin embargo, la violencia contra la integridad física es inmanente a los paramilitares (35). Estos, más que cualquier otro grupo armado, implementan un repertorio de terror basado en masacres, asesinatos selectivos, tortura, desapariciones, desplazamientos forzados, bloqueos económicos y violencia sexual que afecta de manera sobre todo a la población campesina (35). 
12. Para mayor información, visitar el sitio web del Ministerio de Justicia de Colombia. Exactamente la sesión: "Ley de Justicia y Paz: respuestas a sus preguntas" http://www.justiciatransicional.gov.co/ABC/Ley-de-Justicia-y-Paz.

13. Las versiones libres son los escenarios que la Ley de Justicia y Paz dispone para la enunciación de la verdad. En ellas, los postulados a la ley confiesan, a cambio de beneficios judiciales, crímenes que les han sido previamente imputados. Tanto en las audiencias de imputación de cargos, como en las de versión libre, las víctimas o sus representantes legales están presentes en unas salas alternas en las que se televisa la confesión. En algunos casos las víctimas (desde la sala alterna) pueden formular preguntas que el juez lee si considera que son pertinentes, pero sus intervenciones son siempre limitadas, ya que o deben estar al servicio de la verdad procesal o deben estar relacionadas con los cargos imputados (los cuales no necesariamente se corresponden con todos los crímenes realizados, a lo sumo con los confesados) (Becerra 2007, 1).

14. Rubiano se inspira en un hecho ocurrido el 27 de febrero de 1997 en Bijao Cacarica, Chocó, en donde el bloque paramilitar Elmer Cárdenas, comandado por "El Alemán," decapitó a Marino López, un agricultor del lugar, y jugó fútbol con su cabeza. "El Alemán" y varios paramilitares han reconocido la decapitación, pero han negado el partido de fútbol, afirmando que se trata de una exageración de los testigos. Ver: http://reconciliacioncolombia.com/web/historia/2330/marino-lopez-el-campesino-con-cuya-cabeza-jugaron-futbol-los-paramilitares

15. Me refiero al olvido que se trata de introducir para ocultar o negar la existencia o responsabilidad sobre un hecho atroz, ya sea por parte del Estado o de una persona particular (Jelin 2002, 29). Hay, sin embargo, otro tipo de olvido que debe ser entendido como duelo, una suerte de "dejar ir...", que tiene una función sanadora y liberadora no despreciable en los procesos individuales y colectivos de paz (Jelin 2002, 32). Sin embargo, este olvido es y corresponde solo a la voluntad de las víctimas. Solo las víctimas pueden dar la pauta para determinar qué es preciso recordar y qué se debe olvidar. Ver: De Greiff, Pablo. 2007. “La obligación moral de recordar.” En Cultura política y perdón, editado por Adolfo Chaparro, 160-174. Bogotá: Universidad del Rosario.

16. Como bien me lo han señalado algunos colegas, este artículo carece de una reflexión detallada sobre lo espectral en el contexto sociocultural colombiano. También he dejado de lado un análisis transnacional de las relaciones amplias y consolidadas entre espectro y teatro en el marco de las desapariciones de carácter político en Latinoamérica. Ambos trabajos son, sin duda, necesarios para entender a cabalidad la presencia de lo espectral en nuestra producción cultural sobre la violencia. Sin embargo, en esta oportunidad, una investigación que involucre ambos temas supera los propósitos introductorios del presente texto y las normativas metodológicas de extensión que lo cobijan. Espero que lo que aquí es una carencia, pueda ser pronto tratado en otro texto de mi autoría. 